\title{
A Framework Analysis for Lean Transformation: A Case Study of a Public Utility in Greece
}

\author{
Yannis A. Pollalis, Michail K. Angelopoulos \\ Department of Economics, University of Piraeus, Piraeus, Greece \\ Email: yannis@unipi.gr, mangelopoulos66@gmail.com
}

How to cite this paper: Pollalis, Y.A. and Angelopoulos, M.K. (2021) A Framework Analysis for Lean Transformation: A Case Study of a Public Utility in Greece. Open Journal of Applied Sciences, 11, 469-488. https://doi.org/10.4236/ojapps.2021.114034

Received: March 14, 2021

Accepted: April 18, 2021

Published: April 21, 2021

Copyright $\odot 2021$ by author(s) and Scientific Research Publishing Inc. This work is licensed under the Creative Commons Attribution International License (CC BY 4.0).

http://creativecommons.org/licenses/by/4.0/

(c) (i) Open Access

\begin{abstract}
Purpose: Nowadays, the worldwide economic recession has created numerous challenges in the Public Sector of Greece, which in turn affect the sustainability of public enterprises. Overall, there is a high pressure to increase productivity and reduce operating costs. The need to adapt to the new environment is pushing public organizations to implement Lean Management strategies in accordance with Private Sector standards. However, the limited budget, public deficits and debts, bureaucratic culture, political dependence and lack of transparency present several issues. These pose a serious threat to successful implementation of Lean practices in the long-run. Lack of relevant research and dichotomous role of public service organizations make this study very interesting. This research paper is aiming at exploring and highlighting the impact of the most important Critical Success Factors (CSFs) for the effective integration of Lean Management principles in Public Utility organizations in Greece by combining bibliographic research and empirical-with the quantitative method-research through case studies. Research Methodology: The research method combines bibliographic research and empirical-with the quantitative method. Quantitative method was employed on a sufficient sample of public employees from two of the largest public companies of Greece: Public Power Corporation (PPC S.A.) and Athens Water Supply and Sewerage Company (EYDAP S.A.) in order to investigate the impact of the most important CSFs on successful Lean Transformation of them. Findings: Quantitative findings from this research illustrated that the most important CSFs that have a positive impact on successful Lean Transformation on Greek public organizations/utilities are: Effective Communication, flexible Organizational Infrastructure, Customer Focus, Linking Lean to Suppliers, Business Plan and Vision, competent Change Management, Top Management Support and Com-
\end{abstract}


mitment, Training and Education, as well as Selection of Staff. On the contrary, the existence of a bureaucratic Organizational Culture has a negative effect on successful integration of Lean Management. Limitations: Important limitations of this study are the utilization of a convenience sample and the strict focus on Greek public organizations operating in a competitive environment.

\section{Keywords}

Lean Management, Public Organizations/Utilities, Critical Success Factors

\section{Introduction}

According to Mc Kinsley study conducted in 974 public organizations, the transformation of the public sector, ascertained that only $39 \%$ of the sample adopted the Lean Management practices to a viable level [1]. The main cause of failure of the aforementioned actions was the absence of frequent control. Although the issue of saving resources in the public sector has been preoccupying academics for many years, Lean Management constitutes a relevantly current issue, given the continuous technological advancements that constantly modify the implemented practices and strategies [2]. According to the findings of Gebre et al. [1] the presence of various Critical Success Factors (CSFs) is considered vital for the accomplishment of viable integration.

Based on Antony et al. [3] every attempt to intergrade the principles of Lean Management must be developed individually depending on the needs of each enterprise and its employees. Simultaneously, the correlation between these specific principles and the organizational aspects of the corporation is considered of outmost importance. Though the Lean principles are more or less the same for the entire business sector, each attempt of incorporation is unique and specific for every organization [4].

However, taking into account that the foresaid individualization can be achieved by CSFs, their exact specification, as far as it concerns Lean management, is rather imperfect [5]. Additionally, there are scarcely any references in international bibliography which adjust CSFs to the public sector and more specifically to the case of Greece [5] [6] [7], as most research conducted are centralized in the private sector.

Taking advantage this specific research gap, the aim of the current research study, is to highlight the impact of the Critical Success Factors-CSFs, in the successful integration of the Lean Market into public companies. The quantitative findings of this research will lead to the development of various practices and strategies that will assist the senior management of the public corporations and the ones responsible for the formation of public policy to successfully intergrade the principles of Lean Management, in order for the effectiveness and the quality of the services offered to citizens to be improved. 


\section{Literature Review}

Critical Success Factors are defined as "the basic factors of multiple sectors of activity, whose results are considered absolutely necessary for a senior executive, in order to accomplish the organizational targets" [8]. This definition makes it clear that CSFs do not only attract researchers' interest but also that of the business managers' [9]. Additionally, it must be noticed they comprise essential clues for the detection and prioritization of the factors that could affect the successful implementation of the Lean Management principles [10].

The strategic importance of the CSFs is evident, since they can increase the possibility for success, related to the limited use of resources and the reduction of running costs of a company and also they can contribute to the evasion of confusion that might occur in the company, due to the implementation of programs aiming at the constant amelioration [11].

Quite recently, researchers such as Juliani and De-Oliveira [5], Lande et al. [12], Manville et al. [13], Netland [14], Psomas [7] and Yadav et al. [10], are carrying out studies to pinpoint the CSFs in a business that will lead to the successful implementation of Lean Management programs, while preserve the resources. In particular it worth's mentioning, that the number of research examining the importance of CSFs for the successful implementation of Lean management in public enterprises is rather limited.

In Table 1 the most vital CSFs tracked down in recent international bibliography are presented.

Garg and Garg [19] classified CSFs in Organizational Individual-related and Project-related Factors. The category of Organizational Factors consists of Business Strategy, Communication, Customer Focus, Organizational Culture and Organizational Infrastructure. The category of Human Factors is divided into Selection of Staff, Training \& Education, while the category of factors related to the project are referring to the Project Management, Management Commitment \& Leadership. At this point it needs to be highlighted, that every researcher describes the failure or the success of the Lean Management implementation from different perspectives, which are classified in two categories: 1) giving emphasis on the work itself 2) to the accomplished results [20] [21]. The first defines the success or the failure focusing on specific crucial factors of work, such as the cost or the time needed for its completion. The second focuses on the expected aims of work, like the merging of the organizational data, the most efficient decision taking and the most fruitful in-company communication [20] [22] [23].

According to all the above and the research performed by Finney and Corbett [24] and Psomas [7] the CSFs which are more frequently mentioned in international bibliography per category are:

\section{Organizational Related Factors}

Project Communication

Organizational Infrastructure

Supplier Focus

Customer Focus
Business Process Reengineering

Business Plan \& Vision

Business Strategy

Change Management 
Table 1. Critical Success Factors (CSFs) of lean management.

\begin{tabular}{|c|c|}
\hline Research & CSFs \\
\hline Jayaraman and Teo [15] & $\begin{array}{l}\text { Project Management, Training and Education, Management } \\
\text { Commitment and Leadership, Communication), Selection of Staff }\end{array}$ \\
\hline Hilton and Sohal [16] & $\begin{array}{l}\text { Project Management, Training \& Education, Management } \\
\text { Commitment and Leadership, Business Strategy, Communication, } \\
\text { Organizational Culture, Selection of Staff }\end{array}$ \\
\hline Laureani and Antony [17] & $\begin{array}{l}\text { Project Management, Training and Education, Management } \\
\text { Commitment and Leadership, Business Strategy, Communication, } \\
\text { Customer Focus, Organizational Culture, Selection of Staff, } \\
\text { Organizational Infrastructure }\end{array}$ \\
\hline Manville et al. [13] & $\begin{array}{l}\text { Project Management, Training and Education, Management } \\
\text { Commitment and Leadership, Business Strategy, Communication, } \\
\text { Customer Focus, Organizational Infrastructure }\end{array}$ \\
\hline Timans et al [18] & $\begin{array}{l}\text { Project Management, Training \& Education, Management } \\
\text { Commitment and Leadership, Communication, Customer Focus, } \\
\text { Organizational Culture, Organizational Infrastructure }\end{array}$ \\
\hline Lande et al. [12] & $\begin{array}{l}\text { Training, Management Involvement and Commitment, Customer } \\
\text { Satisfaction, Leadership, Project Prioritization and Selection, } \\
\text { Cultural Change, Understand Lean Six Sigma (LSS) Methodology, } \\
\text { Strategic Quality Planning, Process Management, Product Design, } \\
\text { Customer Focus, Business Strategy, Employee Satisfaction, } \\
\text { Employee Reward, Inventory Control, Communication, Linking } \\
\text { LSS to Employees, Linking LSS to Suppliers, Employee } \\
\text { Empowerment, Quality Measurement System, Benchmarking, } \\
\text { Total Quality Management }\end{array}$ \\
\hline Juliani and de-Oliveira [5] & $\begin{array}{l}\text { Business Strategy \& Rule Abidance, Project Management and } \\
\text { Budget Keeping, Business Strategy and Efficient Supply, } \\
\text { Communication and User Focus, Selection of Staff and } \\
\text { Efficient Supply }\end{array}$ \\
\hline
\end{tabular}

\section{Project Related Factors}

Project Management

Management Commitment \& Leadership

Top Management Support

\section{Human Related Factors}

Selection of Staff

\section{Training \& Education}

Organizational Culture

The current research is focusing on the impact of these factors on the successful Lean Transformation of public companies.

\section{Research Question}

The unsatisfactory implementation and function of the factors that this research characterized as Lean Management CSFs, leads to the failure of the overall attempt aiming at the reshaping of a public corporation. So, the research question of great value which must be answered, is related to the investigation of the role and the effects of CSFs on the implementation of Lean Management on public companies. The severe deficiency of bibliography and worldwide practice makes this research of outmost importance. 


\section{Research Methodology}

This paper, combines bibliographic research and empirical -with the quantitative method-research through case studies. More specifically, with extensive and thorough bibliographic research the most important CSFs were determined and via quantitative approach the above question was answered. The sample research with standardized questionnaire, was performed in two of the biggest and most important public companies in Greece, the Public Power Corporation S.A. (PPC S.A.) and the Athens Water Supply and Sewerage Company (EYDAP S.A).

The quantitative approach is based on sample research with standardized questionnaire, offering the ability to approach a satisfactory proportion of the population for the investigation of theories and inquiries [25]. The questionnaire was created based on surveys of companies in South Africa, Australia, China, Canada and Belgium which investigated the most important impact factors in six sigma and lean six sigma transformations.

The questionnaire constitutes the most fundamental tool concerning the data collection in a quantitative research. Planning and conducting this questionnaire, for the specific study, was actualized oriented to the materialization of the goals of the research at the two biggest Greek enterprises of public interest and utility purpose: PPC S.A. and EYDAP S.A. It was based on multiple rules, in order for the questions not to be biased and lead to erroneous outcome [26].

In order for the respondents to remain impartial, there was appropriate combination and composition of questions along with the capitalization of appropriate scales. More specifically, the questions were mixed, so that the participants would find challenging to set apart the individual and the dependent variable of the research. A convenience sample, which is characterized by low cost and time of realization was used, which when performed properly it can reduce the chance of a statistic error [26]. This is a method of no-odds where the subjects of the research are chosen based on their proximity and easy accessibility [27] and it is the most popular when concerning workforce since it is feasible to include the vast majority of the population. Simultaneously, the method of snowball sampling was utilized, during which it was asked from the participants to forward the questionnaire to their colleagues working in the same sector. To be more exact, the procedure of sampling used in the current research is the following:

Population:

The employees in public companies (PPC S.A., EYDAP S.A) occupied in Directorates and Sectors such as: IT, operations, energy, management, strategic planning, research, human resource management, marketing and procurement.

\section{Sample size:}

From the 480 questionnaires being handed out, 343 valid answers were collected. Consequently, the response rate was $71.5 \%$.

Realization of sampling plan and collection of data:

Sampling was performed in the aforementioned Directorates and Sectors from January 2019 till September 2019. The research was being conducted in the 
morning and at noon, in order to ensure a satisfactory representation of the sample. The delivery of the questionnaire was performed both traditionally (hand by hand) and online. The online distribution of the questionnaire was made according to the lists of the e-mails given to the human resources Directorate of each company. At this point it worth's mentioning that we took advantage of snowball sampling, as it was asked from the participants to hand out the questionnaire to their colleagues.

Procedure of codification and insert of data:

The variables of the research (dependent variables CSFs, independent variable Lean Transformation) include various scales, such as the Likert scale. The possible alternatives were coded using relevant numbers and headlines with the assistance of "Microsoft Excel" spreadsheet. Moreover, the data from the participants' responses were inserted on a data basis "SPSS Version 23 for Windows", always in accordance with the previously mentioned codification. Finally, the data were analyzed with the aid of the specific statistic package and the "IBM SPSS Amos 21".

\section{Findings}

The normality of the data was checked through normality tests such as the levels skewness and kurtosis of the variables, along with the statistic test Kolmogorov-Smirnov.

Skewness is a measure of symmetry, or more precisely, the lack of symmetry. A distribution, or data set, is symmetric if it looks the same to the left and right of the center point. [28]. On the contrary, Kurtosis is a measure of whether the data are heavy-tailed or light-tailed relative to a normal distribution. That is, data sets with high kurtosis tend to have heavy tails, or outliers. Data sets with low kurtosis tend to have light tails, or lack of outliers. A uniform distribution would be the extreme case.

On the other hand, the statistic test, Kolmogorov-Smirnov, was applied to verify if the sample follows the normal distribution of the population or not. This specific test is considered more trustworthy compared to the detection for Skewness and Kurtosis [29]. For this reason, they are examined in combination in most research studies [30]. In the current thesis it has been noticed that the variables being studied do not comply with the normal distribution, as the p-value is less than $0.05(\mathrm{p}<0.05)$.

Since convenience sample was applied in the current study, meaning that non-random sampling was performed, non-normal distribution is being noticed in Table 2 below, as expected.

\section{Confirmatory Factor Analysis}

The Confirmatory Factor Analysis (CFA) aims at the screening of the prediction rate of a set of suggestions per Critical Success Factor (CSF) for the composition of a uniform scale. The CFA was conducted in the statistic program AMOS, the results of which indicated the existence of an excellent model: $\chi^{2} /$ d.f. $=1.51$ (recommended between 1 and 5), CFI (Comperative Fit Index) = 
Table 2. Control of sample distribution.

\begin{tabular}{|c|c|c|c|c|c|c|}
\hline & \multirow{2}{*}{$\frac{\mathbf{N}}{\text { Statistic }}$} & \multicolumn{2}{|c|}{ Skewness } & \multicolumn{2}{|c|}{ Kurtosis } & \multirow{2}{*}{$\begin{array}{c}\text { Kolmogorov-Smirnov } \\
\mathrm{p}\end{array}$} \\
\hline & & Statistic & $\begin{array}{l}\text { Std. } \\
\text { Error }\end{array}$ & Statistic & $\begin{array}{l}\text { Std. } \\
\text { Error }\end{array}$ & \\
\hline Project Communication & 343 & 0.19 & 0.13 & -0.49 & 0.26 & 0.00 \\
\hline $\begin{array}{l}\text { Organizational } \\
\text { Infrastructure }\end{array}$ & 343 & 0.07 & 0.13 & -0.46 & 0.26 & 0.00 \\
\hline Supplier Focus & 343 & -0.18 & 0.13 & -0.70 & 0.26 & 0.00 \\
\hline Customer Focus & 343 & -0.37 & 0.13 & -0.28 & 0.26 & 0.00 \\
\hline $\begin{array}{l}\text { Business Process } \\
\text { Reengineering }\end{array}$ & 343 & -0.17 & 0.13 & -0.48 & 0.26 & 0.00 \\
\hline Business Plan \& Vision & 343 & 0.05 & 0.13 & -0.55 & 0.26 & 0.00 \\
\hline Business Strategy & 343 & -0.10 & 0.13 & -0.29 & 0.26 & 0.00 \\
\hline Change Management & 343 & 0.20 & 0.13 & -0.46 & 0.26 & 0.00 \\
\hline Top Management Support & 343 & -0.22 & 0.13 & -0.40 & 0.26 & 0.00 \\
\hline $\begin{array}{l}\text { Management Commitment } \\
\text { \& Leadership }\end{array}$ & 343 & -0.30 & 0.13 & -0.25 & 0.26 & 0.00 \\
\hline Project Management & 343 & -0.22 & 0.13 & 0.12 & 0.26 & 0.00 \\
\hline Selection of Staff & 343 & -0.39 & 0.13 & -0.01 & 0.26 & 0.00 \\
\hline Training \& Education & 343 & 0.33 & 0.13 & -0.65 & 0.26 & 0.00 \\
\hline Organizational Culture & 343 & 0.10 & 0.13 & -0.41 & 0.26 & 0.00 \\
\hline Valid N (list wise) & 343 & & & & & \\
\hline
\end{tabular}

0.95 (recommended $\geq 0.93)$, TLI (Tucker-Lewis Index) $=0.93$ (recommended $\geq$ 0.90 ), GFI (Goodness-of-fit Index) $=0.91$ (recommended $\geq 0.90$ ), RMSEA (Root Mean Square Error of Approximation) $=0.04$ (recommended $\leq 0.08$ ), SRMR $($ Standardized Root Mean Squared Residual) $=0.04($ recommended $\leq 0.08)[31]$ [32].

According to Table 3, the standardized factor loadings in the SuggestionsAnswers (e.g. COMMUNICATION1, COMMUNICATION2,

COMMUNICATION3, COMMUNICATION4, COMMUNICATION5) per ScaleCSF (e.g. Project Communication) that the CFA confirmed, ranged between 0.65 and 0.93 . The previously mentioned loadings displayed a satisfactory level of statistic importance, as $\mathrm{p}<0.001$. Therefore, the model is characterized by acceptable levels of convergent validity.

On the other hand, having as an ultimate target the further investigation of the credibility of each factor the indicator Composite Reliability (CR) was applied. This particular indicator is performed based on the tables produced by the CFA and AMOS. More specifically, the scales displayed a score between 0.71 and 0.90 . As a result, in any case the $\mathrm{CR}$ indicator was above 0.60 which is the least permissible limit [33]. Table 3 which follows, presents the results of CFA. 
Table 3. Findings of Confirmatory Factor Analysis (CFA).

\begin{tabular}{|c|c|c|}
\hline $\begin{array}{c}\text { CSFs } \\
\text { (Scales \& Suggestions per Scale) }\end{array}$ & $\begin{array}{c}\text { Standardized } \\
\text { Factor Loadings }\end{array}$ & $\begin{array}{l}\text { Composite Reliability } \\
\text { (CR) }\end{array}$ \\
\hline Project Communication & & 0.82 \\
\hline COMMUNICATION 1 & 0.78 & \\
\hline COMMUNICATION 2 & 0.80 & \\
\hline COMMUNICATION 3 & 0.79 & \\
\hline COMMUNICATION 4 & 0.81 & \\
\hline COMMUNICATION 5 & 0.85 & \\
\hline Organizational Infrastructure & & 0.79 \\
\hline STRUCTURE 1 & 0.79 & \\
\hline STRUCTURE 2 & 0.83 & \\
\hline STRUCTURE 3 & 0.65 & \\
\hline STRUCTURE 4 & 0.82 & \\
\hline Supplier Focus & & 0.78 \\
\hline SUPPLIER 1 & 0.80 & \\
\hline SUPPLIER 2 & 0.87 & \\
\hline SUPPLIER 3 & 0.81 & \\
\hline Customer Focus & & 0.86 \\
\hline CUSTOMER 1 & 0.93 & \\
\hline CUSTOMER 2 & 0.89 & \\
\hline CUSTOMER 3 & 0.87 & \\
\hline Business Process Reengineering & & 0.89 \\
\hline REENGINEERING 1 & 0.88 & \\
\hline REENGINEERING 2 & 0.93 & \\
\hline REENGINEERING 3 & 0.90 & \\
\hline Business Plan \& Vision & & 0.90 \\
\hline PLAN_VISION 1 & 0.85 & \\
\hline PLAN_VISION 2 & 0.73 & \\
\hline PLAN_VISION 3 & 0.86 & \\
\hline PLAN_VISION 4 & 0.90 & \\
\hline PLAN_VISION 5 & 0.90 & \\
\hline PLAN_VISION 6 & 0.86 & \\
\hline PLAN_VISION 7 & 0.87 & \\
\hline PLAN_VISION 8 & 0.81 & \\
\hline PLAN_VISION 9 & 0.88 & \\
\hline Business Strategy & & 0.85 \\
\hline STRATEGY 1 & 0.83 & \\
\hline STRATEGY 2 & 0.82 & \\
\hline STRATEGY 3 & 0.78 & \\
\hline STRATEGY 4 & 0.88 & \\
\hline
\end{tabular}




\section{Continued}

\begin{tabular}{|c|c|c|}
\hline Change Management & & 0.89 \\
\hline CHANGE 1 & 0.80 & \\
\hline CHANGE 2 & 0.79 & \\
\hline CHANGE 3 & 0.82 & \\
\hline CHANGE 4 & 0.91 & \\
\hline CHANGE 5 & 0.80 & \\
\hline CHANGE 6 & 0.74 & \\
\hline CHANGE 7 & 0.65 & \\
\hline Top Management Support & & 0.84 \\
\hline SUPPORT 1 & 0.77 & \\
\hline SUPPORT 2 & 0.88 & \\
\hline SUPPORT 3 & 0.84 & \\
\hline SUPPORT 4 & 0.83 & \\
\hline SUPPORT 5 & 0.70 & \\
\hline Management Commitment \& Leadership & & 0.90 \\
\hline COMMITMENT 1 & 0.88 & \\
\hline COMMITMENT 2 & 0.89 & \\
\hline COMMITMENT 3 & 0.87 & \\
\hline COMMITMENT 4 & 0.76 & \\
\hline COMMITMENT 5 & 0.89 & \\
\hline Project Management & & 0.89 \\
\hline PROJECT 1 & 0.87 & \\
\hline PROJECT 2 & 0.86 & \\
\hline PROJECT 3 & 0.88 & \\
\hline PROJECT 4 & 0.89 & \\
\hline PROJECT 5 & 0.90 & \\
\hline Selection of Staff & & 0.88 \\
\hline SELECTION 1 & 0.87 & \\
\hline SELECTION 2 & 0.88 & \\
\hline SELECTION 3 & 0.82 & \\
\hline SELECTION 4 & 0.89 & \\
\hline SELECTION 5 & 0.73 & \\
\hline Training \& Education & & 0.89 \\
\hline TRAINING 1 & 0.81 & \\
\hline TRAINING 2 & 0.82 & \\
\hline TRAINING 3 & 0.88 & \\
\hline TRAINING 4 & 0.89 & \\
\hline TRAINING 5 & 0.84 & \\
\hline TRAINING 6 & 0.90 & \\
\hline Organizational Culture & & 0.81 \\
\hline CURTURE 1 & 0.85 & \\
\hline CURTURE 2 & 0.87 & \\
\hline CURTURE 3 & 0.76 & \\
\hline CURTURE 4 & 0.79 & \\
\hline
\end{tabular}


Equally, for the multicollinearity check among the CSFs/Scales, a regression analysis was performed taking advantage the Variance Inflation Factor (VIF). This particular indicator tests the existence of inner correlation among the utilized scales. When the indicators VIF $>10$, then multicollinearity discrepancies are occurring, consequently the indicator $\mathrm{R}^{2}$ ( $\mathrm{R}$ Squared) is over 0.90 . In the case of the current research severe $\mathrm{R}^{2}$ multicollinearity problems were not spotted among the scales since the indicator VIF $<10$. However, even if in some cases prices $>3$ and $<5$ were detected, they did not cause serious worries, as the Tolerance $>0.2$, revealing the absence of standard errors into the regression analysis. Tables 4-6 that follow present the results of the multicollinearity tests among the Scales/CSFs.

The Confirmatory Factor Analysis showed 14 Scales/CSFs in total. For the descriptive analysis of the scales various descriptive measurements were used, such as average, standard deviation, maximum and minimum. The correspondence of the average was performed based on the five-point scale of Likert type (1: I totally disagree - 5: I totally agree) and more particularly as follows:

Table 4. Test multicollinearity of the organizational factors*.

\begin{tabular}{ccc}
\hline Scales/CSFs & Coefficient Tolerance & Indicator VIF \\
\hline Project Communication & 0.29 & 3.53 \\
Organizational Infrastructure & 0.33 & 3.01 \\
Supplier Focus & 0.37 & 2.74 \\
Customer Focus & 0.51 & 2.00 \\
Business Process Reengineering & 0.28 & 3.60 \\
Business Plan \& Vision & 0.24 & 3.93 \\
Business Strategy & 0.28 & 3.57 \\
Change Management & 0.22 & 3.60 \\
\hline
\end{tabular}

*Dependent variable: Lean transformation.

Table 5. Test multicollinearity of the Project factors ${ }^{\star}$.

\begin{tabular}{ccc}
\hline Scales/CSFs & Tolerance indicator & Indicator VIF \\
\hline Top Management Support & 0.24 & 3.17 \\
Management Commitment \& Leadership & 0.22 & 3.67 \\
Project Management & 0.38 & 2.67 \\
\hline
\end{tabular}

*Dependent variable: Lean transformation.

Table 6. Test multicollinearity of the human factors*.

\begin{tabular}{ccc}
\hline Scales/CSFs & Tolerance indicator & Indicator VIF \\
\hline Selection of Staff & 0.43 & 2.31 \\
Training \& Education & 0.42 & 2.36 \\
Organizational Culture & 0.43 & 2.34 \\
\hline
\end{tabular}

*Dependent variable: Lean transformation. 
- Prices ranging from 0.45 - 1.44 reveal that the majority of the respondents stated they totally disagree.

- Prices ranging from 1.45 - 2.44 showed that the majority of the respondents stated that they disagree.

- Prices ranging from 2.45 - 3.44 showed that the majority of the respondents stated that they neither agree nor disagree.

- Prices from 3.45 - 4.44 showed that the majority of the respondents stated that they agree

- Prices from 4.45 - 5 showed that the majority of the respondents stated that they totally agree

In general, the average of the scales in the present research ranged from 2.39 (disagree) to 3.15 (neither disagree/nor agree). For example, the vast majority of respondents stated that they disagree (average $=2.39$ ) as far as it concerns the fact that detailed training and empirical seminars are provided, concerning the resource saving principles. Furthermore, neutral opinions were expressed to the statements of the remaining factors. A characteristic example is the fact that the majority of the respondents said that they neither agree nor disagree (average = 3.07) concerning the Management Commitment for the adoption of resource saving practices. For more evidence with regard to the average of the Scales/ CSFs Table 7 is cited.

For a complete examination of the Research Question the Structural Equation Modeling (SEM) method in AMOS was used, in combination with the multiple regression analyses in SPSS. In this way more credible and spherical models were produced for the examination of the effect of the CSFs in the fruitful Lean Transformation.

Table 7. Descriptive measurements scales/CSFs.

\begin{tabular}{cccccc}
\hline Scales/CSFs & $\mathrm{N}$ & minimum & maximum & $\begin{array}{c}\text { Standard } \\
\text { average } \\
\text { deviation }\end{array}$ \\
\hline Project Management & 343 & 1 & 5 & 2.77 & 0.91 \\
Organizational Infrastructure & 343 & 1 & 5 & 3.09 & 0.88 \\
Supplier Focus & 343 & 1 & 5 & 3.00 & 0.91 \\
Customer Focus & 343 & 1 & 5 & 3.11 & 0.96 \\
Business Process Reengineering & 343 & 1 & 5 & 2.97 & 0.97 \\
Business Plan \&Vision & 343 & 1 & 5 & 2.63 & 0.91 \\
Business Strategy & 343 & 1 & 5 & 3.03 & 0.89 \\
Change Management & 343 & 1 & 5 & 2.50 & 0.89 \\
Top Management Support & 343 & 1 & 5 & 3.15 & 0.93 \\
Ering & 343 & 1 & 5 & 3.07 & 0.93
\end{tabular}


The effect of CSFs on the Successful Integration of the Lean Management (Lean Transformation)

The first model to be created through SEM is focusing on the connection between the CSFs and the successful incorporation of the Lean Management (Lean Transformation) principles. Specifically, it was considered particularly trustworthy given that the model fit indicators were more than enough: $\chi^{2} /$ d.f. $=2.01, \mathrm{CFI}=$ $0.96, \mathrm{TLI}=0.90, \mathrm{GFI}=0.94, \mathrm{RMSEA}=0.05, \mathrm{SRMR}=0.04[33]$. The degree of influence of the independent variables (factors CSFs) on the dependent (Lean Transformation) is estimated by Standardized Regression Weights indicator $(\beta)$, for which minimum acceptable levels do not exist, as long as there is statistically notable influence ( $\mathrm{p}<0.05$ or $\mathrm{p}<0.01$ depending on the results of each type of analysis). In case an unsatisfactory level of statistic notability is failed to be traced, then the independent variable does not affect the dependent variable. On the whole, there is positive or negative connection depending on the sign of indicator $\beta$, whereas the specification of the effect is actualized based on the following limits [34]:

$$
\begin{array}{ll}
\beta>0.8, \text { strong effect } & \beta \leq 0.6, \text { average to strong effect } \\
\beta \leq 0.4, \text { average effect } & \beta \leq 0.2 \text {, weak effect }
\end{array}
$$

Additionally, the existence of a satisfactory degree of $\mathrm{R}^{2}$ indicator is deemed essential. When $R^{2}$ reaches 1 it suggests that the effect of the independent variables on the dependent variable is even more perfect [35].

In the overall model of the current research, the $\mathrm{R}^{2}$ indicator of the dependent variable Lean Transformation came up to 0.86 . That means that the $86 \%$ of the fickleness of the Successful Lean Transformation depends on the statistically important CSFs. The Organizational Factors which emerged through SEM and have a statistically important level of impact on the independent variable are the following: Project Communication $(\beta=0.19, \mathrm{p}=0.03<0.05)$, Organizational Infrastructure $(\beta=0.14, \mathrm{p}=0.01<0.05)$, Supplier Focus $(\beta=0.15, \mathrm{p}=0.01<$ $0.05)$, Supplier Customer $(\beta=0.27, \mathrm{p}=0.001<0.01)$, Business Plan $\&$ Vision $(\beta$ $=0.31, \mathrm{p}=0.001<0.01)$ and Change Management $(\beta=0.88, \mathrm{p}=0.001<0.01)$. From the above factors, the Project Communication, the Organizational Infrastructure and the Supplier Focus, influence positively, statistically importantly and to a miniscule degree the Successful Lean Transformation. On the contrary, the Customer Focus, the Business Plan \& Vision influence positively and affect averagely. Additionally, it was found that the Change Management foresees positively leading at a higher level the Lean Transformation. Though, the Business Process Reengineering $(\mathrm{p}=0.88>0.05)$ and the Business Strategy $(\mathrm{p}=0.12>$ 0.05 ) have been noticed not to affect in a statistically way the level of the dependent variable (Lean Transformation).

The Project Factors that have a statistically significant result from an average to high level the Successful Incorporation Lean Management principles are Commitment Management \& Leadership $(\beta=0.47, \mathrm{p}=0.001<0.01)$ and Top Management Support $(\beta=0.52, \mathrm{p}=0.001<0.01)$. Still, Project Management was found not to affect at a statistically important degree, given that the indicator $\mathrm{p}=$ 
$0.95>0.05$. Nevertheless, all the Human Factors pose a statistically important influence on the dependent variable. More explicitly, Training \& Education $(\beta=$ $0.41, \mathrm{p}=0.001<0.01)$, along with Selection of Staff $(\beta=0.38, \mathrm{p}=0.001<0.01)$ leverage positively and in average degree in favour of Lean Transformation. What made an impression though, is the negative and statistically important influence of the Organizational Culture $(\beta=-0.13, \mathrm{p}=0.001<0.01)$ on the Successful Lean Transformation. As a consequence, this hitches the successful transformation towards the Lean Principles.

Table 8 that follows depicts the immediate effects of the CSFs on the Successful Lean Transformation and forms a successful model of installation, taking advantage the SEM method. At this point it is worthwhile to mention that the $\mathrm{t}$-value indicator measures the intensity of the variance in the size of the sample.

Table 8. Direct influence of the CSFs on the lean transformation.

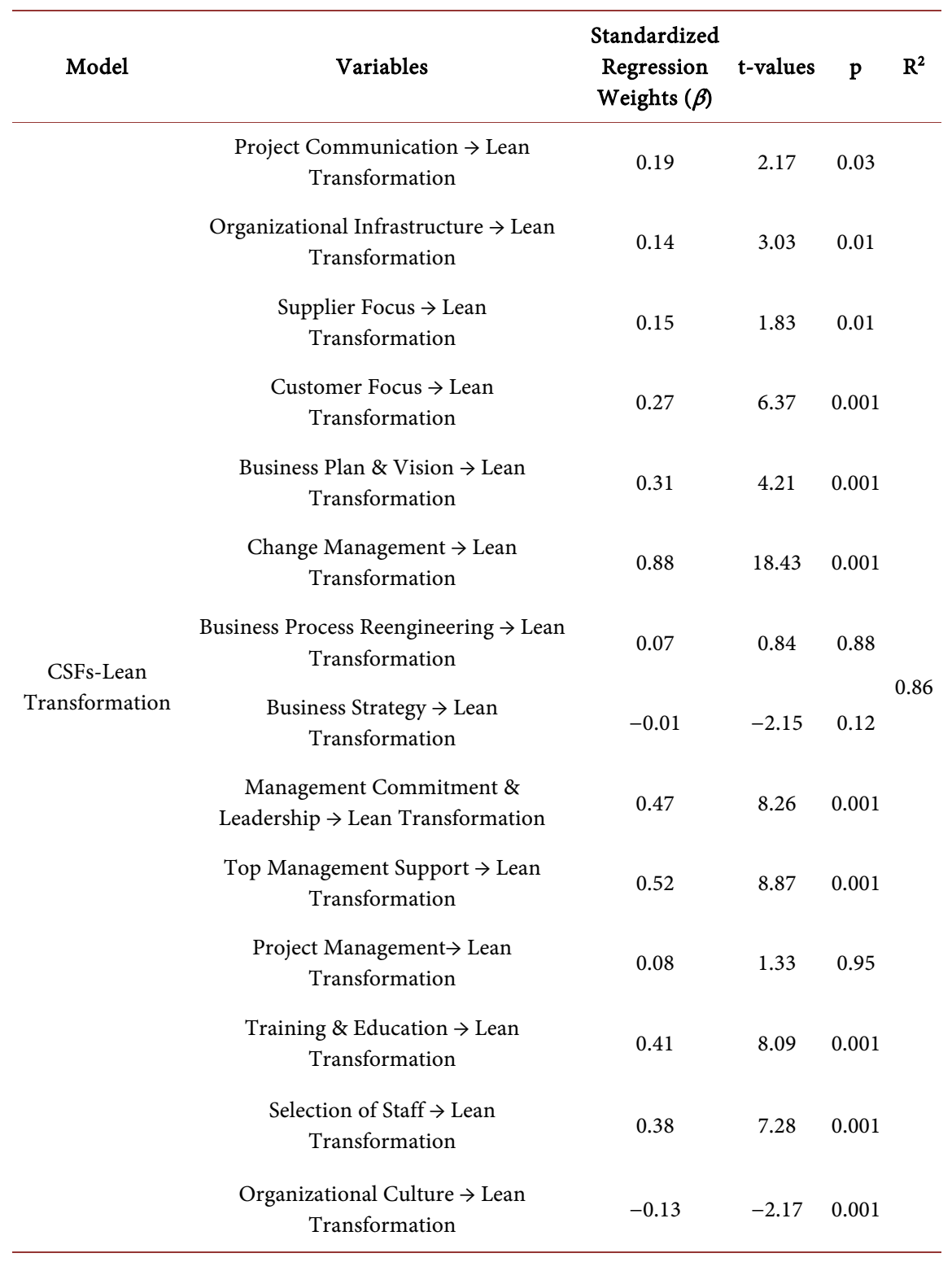


In other words, it refers to the size of the standard error. The greater this specific indicator is, the larger the possibility of accepting our research hypothesis and not reject it.

On the contrary, the multiple regression analysis between the Organizational Factors and the Successful Integration of the Lean Management Principles indicated that the Organizational Infrastructure $(\beta=0.11, \mathrm{p}=0.04<0.05)$, the Supplier Focus $(\beta=0.11, \mathrm{p}=0.02<0.05)$, the Customer Focus $(\beta=0.14, \mathrm{p}=0.00<$ $0.05)$, the Business Plan $\&$ Vision $(\beta=0.28, \mathrm{p}=0.00<0.05)$ and the Change Management $(\beta=0.23, \mathrm{p}=0.00<0.05)$ have a positive and statistically substantial influence. The Business Strategy $(\beta=-0.03, \mathrm{p}=0.18>0.05)$, the Business Process Reengineering $(\beta=0.08, \mathrm{p}=0.14>0.05)$ and the Project Communication $(\beta=0.01, \mathrm{p}=0.89>0.05)$, however, do not pose a statistically important effect on the Lean Transformation. Even though, Project Communication through the regression analysis failed to show that influences on a statistically important level when combined with the rest organizational factors, however, in SEM something like that is not true (Table 9).

\section{Regression Model of Organizational Factors:}

Lean Transformation $=0.11$ (Organizational Infrastructure $)+0.11$ (Supplier Focus) +0.14 (Customer Focus) + 0.28 (Business Plan \& Vision) + 0.23 (Change Management)

$\mathrm{R}^{2}=0.70$, verifying that $70 \%$ of the Successful Integration of the Lean Management depends on the statistically importance of Organizational Factors.

Additionally, the multiple regression analysis between the Project Factors and the Successful integration of the Lean Management (Lean Transformation) Principles depicted that all the factors influence statistically importantly. More specifically, as independent variables the Scales (CSFs), "Top Management Support", "Management Commitment \& Leadership" and "Project Management" were applied, while as dependent variable the "Lean Transformation". The results of this particular analysis concluded that the Project Management positively affects, from an average to a high degree $(\beta=0.39, \mathrm{p}=0.00)$ the Successful Integration of the Lean Management. This finding is contradictory to the SEM analysis, which revealed that this specific factor does not impose a statistically important impact, when combined with all the CSFs. Furthermore, the Management Commitment \& Leadership was proven to have a positive impact, statistically important and average $(\beta=0.34, \mathrm{p}=0.00)$ to the Lean Transformation. On the contrary, the Top Management Support affects positively and to the minimum $(\beta=0.16, p=0.01)$ the Successful Integration of the Lean Management/Resources Saving Principles (Table 10).

Regression Model of Project Factors:

Lean Transformation $=0.39$ (Project Management) +0.34 (Management Commitment \& Leadership) + 0.16 (Top Management Support).

The total dependence of Lean Transformation on the aforementioned Project Factors reaches $68 \%$, given that the $\mathrm{R}^{2}=0.68$. 
Table 9. Multiple regression analysis-effect of the organizational factors on lean transformation.

\begin{tabular}{cccc}
\hline Independent Variables* & $\beta$ & $\mathbf{p}$ & $\mathbf{R}^{2}$ \\
\hline Project Communication & 0.01 & 0.89 & \\
Organizational Infrastructure & 0.11 & 0.04 & \\
Supplier Focus & 0.11 & 0.02 & \\
Customer Focus & 0.14 & 0.00 & 0.70 \\
Business Process Reengineering & 0.08 & 0.14 & \\
Business Plan \& Vision & 0.28 & 0.00 & \\
Change Management & 0.23 & 0.00 & \\
Business Strategy & -0.03 & 0.18 & \\
Valid & - & 0.26 & \\
\hline
\end{tabular}

*Dependent variable: Lean transformation.

Table 10. Multiple regression-impact of the project factors on the lean transformation.

\begin{tabular}{cccc}
\hline Independent Variables & $\boldsymbol{\beta}$ & $\mathrm{p}$ & $\mathbf{R}^{2}$ \\
\hline Project Management & 0.39 & 0.00 & \\
Management Commitment \& Leadership & 0.34 & 0.00 & 0.68 \\
Top Management Support & 0.16 & 0.01 & \\
Valid & - & 0.06 & \\
\hline
\end{tabular}

*Dependent variable: Lean transformation.

Table 11. Multiple regression-impact of the project factors on the lean transformation.

\begin{tabular}{cccc}
\hline Independent Variables & $\boldsymbol{\beta}$ & $\mathrm{p}$ & $\mathbf{R}^{2}$ \\
\hline Selection of Staff & 0.49 & 0.00 & \\
Training \& Education & 0.50 & 0.00 & 0.74 \\
Organizational Culture & -0.31 & 0.00 & \\
Valid & - & 0.02
\end{tabular}

${ }^{*}$ Dependent variable: Lean transformation.

The results of the multiple regression analysis concerning the link between the Human Factors and the Successful Integration of the Lean Management Principles unveiled that equally the Training \& Education, along with the Organizational Culture, influence at a statistically important level. Contrary to that, it has emerged that the Training \& Education $(\beta=0.50, \mathrm{p}=0.00)$ and the Selection of Staff $(\beta=0.49, \mathrm{p}=0.00)$ have a positive, from average to powerful influence Lean Transformation. On the other hand, it was proven that the Organizational Culture affects negatively and averagely $(\beta=-0.31, \mathrm{p}=0.00)$ the Successful Integration of the Lean Management. The findings of the multiple regression analysis are shown on Table 11 and right afterwards the relevant regression model.

Regression Model of Human Factors: 
Lean Transformation $=0.49$ (Selection of Staff $)+0.50$ (Training \& Education $)$ - 0.31 (Organizational Culture)

$\mathrm{R}^{2}=0.74$, revealing that $74 \%$ of the overall fluctuation of the Lean Transformation depends on the Training \& Education, the Selection of Staff and the Organizational Culture.

\section{Conclusions}

In conclusion, the present research with the SEM method proves the positive effect of the CSFs (Management Commitment \& Leadership, Training \& Education, Selection of Staff) as well as the very positive strong effect of Change Management, and the negative effect of Organizational Culture on Lean Transformation of public enterprises in Greece. On the other hand with Regression Analysis the research confirms that the CSFs that positively (moderately to strongly) influence the Lean Transformation of public companies and lead to long-term success are: 1) Project Communication, 2) the Organizational Infrastructure, 3) the Supplier Focus, 4) the Customer Focus, 5) the Business Plan \& Vision, 6) the Change Management, 7) the Management Commitment \& Leadership, 8) the Training \& Education, and 9) the Selection of Staff while the Organizational Culture has a negative effect

Moreover, the findings of the quantitative research showed that the Business Strategy, the Business Process Reengineering and the Project Management do not influence on a statistically important degree the effective integration of the Lean Management. Consequently, the conclusions of Manville et al. [13], Angelopoulos and Pollalis [36] who demonstrated that the existence of efficient Project Management is ranked last among numerous factors CSFs, while at the same time does not a play a significant role statistically, were confirmed. Simultaneously, we confirmed the conclusions of Agaoglu et al. [9], who noticed that the Business Process Reengineering and the Business Strategy do not significantly define the successful integration of the Lean principles. On the opposite end of the spectrum, the conclusion reached by Antony and Desai [37], Juliani and de Oliveira [5], Nah et al. [38], Ramayah [39], who verified that the Business Strategy, the Business Process Reengineering and the Project Management have a favorable impact, at a significant level on the successful integration of Lean Management, were turned down.

In the public sector, the lack of strong competition leads to the preservation of obsolete organizational structures, which do not encourage changes and consequently the Business Process Reengineering. According to Weerakkody et al. [40] the public companies do not possess the adequate motivation so as to implement organization alterations and redesign their procedures. More to the point, they experience severe pressures to maintain specific expenditure limits, and as a result they do not pursue extra cost savings since the required budget has been covered [41]. At the same time, due to the intense bureaucratic procedures that characterize the public companies, the senior executive members do not retain 
the ultimate authority/power to proceed into changes of the organizational processes [42]. Furthermore, the occurrence of changes is difficult to be performed without the consent of the involved parties (e.g. the government, regulatory body etc.) as well various legal restrictions and rules hamper the successful redesign of the business procedure towards the Lean principles [43]. Consequently, it is plausible the Business Process Reengineering not to significantly influence the successful integration of the Lean Management.

Additionally, in the current research, it was verified that the Organizational Culture of the public companies, participating in the quantitative research, hinders the successful transformation towards the Lean Management principles. This can be explained from the fact that the majority of the Greek public companies functions according to a bureaucratic culture, which is regulated by lack of efficiency, absence of transparency, scarcity of meritocracy, overloading and obscurity of labor roles [44].

\section{Conflicts of Interest}

The authors declare no conflicts of interest regarding the publication of this paper.

\section{References}

[1] Gebre, B., Hallman, P., Minukas, M. and O’Brien, B. (2012) Transforming Government Performance through Lean Management. McKensey Center for Government. https://cdn.factcheck.org/UploadedFiles/McKinsey.pdf

[2] Asnan, R., Nordin, N. and Othman, S.N. (2016) Success Factors of Lean Management Implementation in Public Service Organization. Journal of Technology and Operations Management, 11, 83-97.

[3] Antony, J., Rodgers, B. and Cudney, E.A. (2019) Lean Six Sigma in Policing Services: Case Examples, Lessons Learnt and Directions for Future Research. Total Quality Management \& Business Excellence, 30, 613-625. https://doi.org/10.1080/14783363.2017.1327319

[4] Lins, M.G., Zotes, L.P. and Caiado, R. (2019) Critical Factors for Lean and Innovation in Services: From a Systematic Review to an Empirical Investigation. Total Quality Management \& Business Excellence, 1-26. https://doi.org/10.1080/14783363.2019.1624518

[5] Juliani, F. and de-Oliveira, O.J.D. (2017) Synergies between Critical Success Factors of Lean Six Sigma and Public Values. Total Quality Management \& Business Excellence, 30, 1563-1577. https://doi.org/10.1080/14783363.2017.1383153

[6] de Almeida, J.P.L., Galina, S.V.R., Grande, M.M. and Brum, D.G. (2017) Lean Thinking: Planning and Implementation in the Public Sector. International Journal of Lean Six Sigma, 8, 390-410. https://doi.org/10.1108/IJLSS-06-2016-0027

[7] Psomas, E. (2016) The Underlying Factorial Structure and Significance of the Six Sigma Difficulties and Critical Success Factors: The Greek Case. The TQM Journal, 28, 530-546. https://doi.org/10.1108/TQM-04-2015-0049

[8] Bullen, C.V. and Rockart, J.F. (1981) A Primer on Critical Success Factors. No 69. Center for Information Systems Research, Massachusetts Institute of Technology, Sloan School of Management, Massachusetts. 
[9] Ağaoğlu, M., Yurtkoru, E.S. and Ekmekçi, A.K. (2015) The Effect of ERP Implementation CSFs on Business Performance: An Empirical Study on Users' Perception. Procedia-Social and Behavioral Sciences, 210, 35-42. https://doi.org/10.1016/j.sbspro.2015.11.326

[10] Yadav, G., Seth, D. and Desai, T.N. (2017) Analysis of Research Trends and Constructs in Context to Lean Six Sigma Frameworks. Journal of Manufacturing Technology Management, 28, 794-821. https://doi.org/10.1108/JMTM-03-2017-0043

[11] Meza, D. and Jeong, K.Y. (2013) Measuring Efficiency of Lean Six Sigma Project Implementation Using Data Envelopment Analysis at NASA. Journal of Industrial Engineering and Management, 6, 401-422. https://doi.org/10.3926/jiem.582

[12] Lande, M., Shrivastava, R. and Seth, D. (2016) Critical Success Factors for Lean Six Sigma in SMEs (Small and Medium Enterprises). The TQM Journal, 28, 613-635. https://doi.org/10.1108/TQM-12-2014-0107

[13] Manville, G., Greatbanks, R., Krishnasamy, R. and Parker, D.W. (2012) Critical Success Factors for Lean Six Sigma Programmes: A View from Middle Management. International Journal of Quality \& Reliability Management, 29, 7-20. https://doi.org/10.1108/02656711211190846

[14] Netland, T.H. (2016) Critical Success Factors for Implementing Lean Production: The Effect of Contingencies. International Journal of Production Research, 54, 2433 2448. https://doi.org/10.1080/00207543.2015.1096976

[15] Jayaraman, K., Teo, K.L. and Soh, K.L. (2012) The Perceptions and Perspectives of Lean Six Sigma (LSS) Practitioners: An Empirical Study in Malaysia. The TQM Journal, 24, 433-446. https://doi.org/10.1108/17542731211261584

[16] Hilton, R.J. and Sohal, A. (2012) A Conceptual Model for the Successful Deployment of Lean Six Sigma. International Journal of Quality \& Reliability Management, 29, 54-70. https://doi.org/10.1108/02656711211190873

[17] Laureani, A. and Antony, J. (2012) Critical Success Factors for the Effective Implementation of Lean Sigma: Results from an Empirical Study and Agenda for Future Research. International Journal of Lean Six Sigma, 3, 274-283.

https://doi.org/10.1108/20401461211284743

[18] Timans, W., Antony, J., Ahaus, K. and van Solingen, R. (2012) Implementation of Lean Six Sigma in Small- and Medium-Sized Manufacturing Enterprises in the Netherlands. Journal of the Operational Research Society, 63, 339-353. https://doi.org/10.1057/jors.2011.47

[19] Garg, P. and Garg, A. (2014) Factors Influencing ERP Implementation in Retail Sector: An Empirical Study from India. Journal of Enterprise Information Management, 27, 424-448. https://doi.org/10.1108/JEIM-06-2012-0028

[20] Amid, A., Moalagh, M. and Ravasan, A.Z. (2012) Identification and Classification of ERP Critical Failure Factors in Iranian Industries. Information Systems, 37, 227-237. https://doi.org/10.1016/j.is.2011.10.010

[21] Hawari, A.A. and Heeks, R. (2010) Explaining ERP Failure in a Developing Country: A Jordanian Case Study. Journal of Enterprise Information Management, 23, 135 160. https://doi.org/10.1108/17410391011019741

[22] Hsu, L.L. and Chen, M. (2004) Impacts of ERP Systems on the Integrated-Interaction Performance of Manufacturing and Marketing. Industrial Management \& Data Systems, 104, 42-55. https://doi.org/10.1108/02635570410514089

[23] Spathis, C. and Ananiadis, J. (2005) Assessing the Benefits of Using an Enterprise System in Accounting Information and Management. Journal of Enterprise Information Management, 18, 195-210. https://doi.org/10.1108/17410390510579918 
[24] Finney, S. and Corbett, M. (2007) ERP Implementation: A Compilation and Analysis of Critical Success Factors. Business Process Management Journal, 13, 329-347. https://doi.org/10.1108/14637150710752272

[25] Taylor, G.R. (2005) Integrating Quantitative and Qualitative Methods in Research. University Press of America, Lanham.

[26] Saunders, M., Lewis, P. and Thornhill, A. (2009) Research Methods for Business Students. Pearson, New York.

[27] Etikan, I., Musa, S.A. and Alkassim, R.S. (2016) Comparison of Convenience Sampling and Purposive Sampling. American Journal of Theoretical and Applied Statistics, 5, 1-4. https://doi.org/10.11648/j.ajtas.20160501.11

[28] Field, A. (2013) Discovering Statistics Using IBM SPSS Statistics. Sage Publications Inc., New York.

[29] Chakravarty, I.M., Roy, J.D. and Laha, R.G. (1967) Handbook of Methods of Applied Statistics. Vol. 1, John Wiley and Sons, Hoboken.

[30] Razali, N.M. and Wah, Y.B. (2011) Power Comparisons of Shapiro-Wilk, Kolmogorov-Smirnov, Lilliefors and Anderson-Darling Tests. Journal of Statistical Modeling and Analytics, 2, 21-33.

[31] Byrne, B.M. (1994) Structural Equation Modeling with EQS and EQS/Windows: Basic Concepts, Applications, and Programming. Sage Publications Inc., New York.

[32] Byrne, B.M. (2001) Structural Equation Modeling with AMOS, EQS, and LISREL: Comparative Approaches to Testing for the Factorial Validity of a Measuring Instrument. International Journal of Testing, 1, 55-86. https://doi.org/10.1207/S15327574IJT0101 4

[33] Bagozzi, R. and Yi, Y. (1988) On the Evaluation of Structure Equation Models. Journal of the Academy of Marketing Science, 16, 74-94. https://doi.org/10.1007/BF02723327

[34] Campbell, M.J., Blackwell, B. and Books, M.J. (2006) Statistics at Square Two. 2nd Edition, Blackwell Publishing/BMJ Books, Oxford.

[35] Voelkl, K.E. and Gerber, S.B. (1999) Using SPSS for Windows: Data Analysis and Graphics. Springer, New York. https://doi.org/10.1007/978-1-4757-3090-6

[36] Angelopoulos, M. and Pollalis, Y. (2019) Critical Success Factors of Lean Management in Public Sector: Evidence from Greece. International Journal of Management and Applied Science, 5, 12-18.

[37] Antony, J. and Desai, D.A. (2009) Assessing the Status of Six Sigma Implementation in the Indian Industry: Results from an Exploratory Empirical Study. Management Research News, 32, 413-423. https://doi.org/10.1108/01409170910952921

[38] Nah, F.F.H., Zuckweiler, K.M. and Lee-Shang Lau, J. (2003) ERP Implementation: Chief Information Officers' Perceptions of Critical Success Factors. International Journal of Human-Computer Interaction, 16, 5-22. https://doi.org/10.1207/S15327590IJHC1601 2

[39] Ramayah, T. (2013) Does the Organizational Culture Act as a Moderator in Indian Enterprise Resource Planning (ERP) Projects? An Empirical Study. Journal of Manufacturing Technology Management, 24, 555-587.

https://doi.org/10.1108/17410381311327404

[40] Weerakkody, V., Janssen, M. and Dwivedi, Y.K. (2011) Transformational Change and Business Process Reengineering (BPR): Lessons from the British and Dutch Public Sector. Government Information Quarterly, 28, 320-328.

https://doi.org/10.1016/j.giq.2010.07.010 
[41] Di Pietro, L., Mugion, R.G. and Renzi, M.F. (2013) An Integrated Approach between Lean and Customer Feedback Tools: An Empirical Study in the Public Sector. Total Quality Management \& Business Excellence, 24, 899-917. https://doi.org/10.1080/14783363.2013.791106

[42] Pollalis, Y. (2014) Sustainable Competitive Advantage in Turbulent Business Environments: Using Critical Organizational Capabilities \& Resources to Manage Complexity. In: Samanta, I., Ed., Strategic Marketing in Fragile Economic Conditions, IGI Global, Hershey, 98-117. https://doi.org/10.4018/978-1-4666-6232-2.ch005

[43] Pollalis, Y. and Frieze, I.H. (1993) A New Look at Critical Success Factors in Information Technology. Information Strategy, 10, 24-34.

[44] Bourantas, D. and Papalexandri, N. (1992) Variables Affecting Organizational Commitment: Private versus Public Owned Organizations in Greece. Journal of Managerial Psychology, 7, 3-10. https://doi.org/10.1108/02683949210012977 